\title{
Understanding the Nucleophilic Character and Stability of the Carbanions and Alkoxides of 1-(9-Anthryl)ethanol and Derivatives
}

\section{Ramsés E. Ramírez ${ }^{1,2}$, Cirilo García-Martínez ${ }^{3}$ and Francisco Méndez ${ }^{2, *}$}

1 Departamento de Fisicomatemáticas, Facultad de Ciencias Químicas, Av. San Claudio y 14 Sur, Col. San Manuel, Benemérita Universidad Autónoma de Puebla, C.P. 72570, Puebla, Pue., Mexico; E-Mail: ramses.ramirez@correo.buap.mx

2 Departamento de Química, División de Ciencias Básicas e Ingeniería, Universidad Autónoma Metropolitana-Iztapalapa, A.P. 55-534, México, D. F., 09340 Mexico

3 Área de Química, Departamento de Ciencias Básicas, Universidad Autónoma Metropolitana-Azcapotzalco, San Pablo \#180, Col. Reynosa, Mexico, D. F., 02200 México; E-Mail: gmc@correo.azc.uam.mx

* Author to whom correspondence should be addressed; E-Mail: fm@xanum.uam.mx; Tel.: +52-55-5804-6400 (ext. 3326); Fax: +52-55-5804-4666.

Received: 3 June 2013; in revised form: 13 August 2013 / Accepted: 16 August 2013 /

Published: 22 August 2013

\begin{abstract}
The nucleophilic character and stability of the carbanions vs. alkoxides derived from 2,2,2-trifluoro-1-(9-anthryl)ethanol and 1-(9-anthryl)ethanol containing $\mathrm{X}$ electron-releasing and $\mathrm{X}$ electron-acceptor substituents attached to $\mathrm{C}-10$, have been studied at the B3LYP/6-31+G(d,p) level of theory. Results analyzed in terms of the absolute gas-phase acidity, Fukui function, the local hard and soft acids and bases principle, and the molecular electrostatic potential, show that the central ring of the 9-anthryl group confers an ambident nucleophilic character and stabilizes the conjugated carbanion by electron-acceptor delocalization.
\end{abstract}

Keywords: absolute gas phase acidity; alkoxide; carbanion; Fukui function; nucleophile 


\section{Introduction}

Pure enantiomers of 2,2,2-trifluoro-1-(9-anthryl)ethanol (1a, Figure 1), are mainly used as chiral solvating agents [1,2] and chiral selectors [1-4] due to their particular hydroxyl (OH) and methine $(\mathrm{CH})$ acidity [5-8]. The calculated gas phase acidities for 1a, 1-(9-anthryl)ethanol (2a) and 2,2,2-trifluoroethanol have shown that the influence of 9-anthryl ring is more significant than the trifluoromethyl group in modifying the $\mathrm{CH}$ rather than the $\mathrm{OH}$ acidity of $\mathbf{1 a}$; the trifluoromethyl group increases $6.0 \mathrm{kcal} \mathrm{mol}^{-1}$ the $\mathrm{OH}$ acidity more than the $\mathrm{CH}$ acidity, while the 9-anthryl group increases $17.0 \mathrm{kcal} \mathrm{mol}^{-1}$ the $\mathrm{CH}$ acidity more than the $\mathrm{OH}$ acidity [6].

Figure 1. 1-(9-anthryl)ethanol and derivatives.

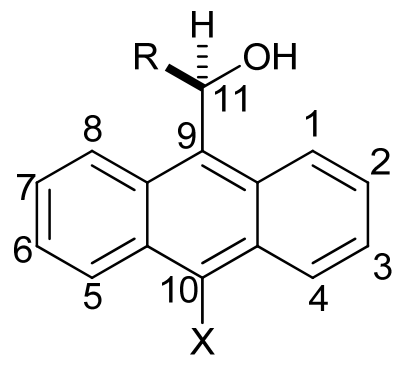
1a, $\mathrm{R}=\mathrm{CF}_{3}, \mathrm{X}=\mathrm{H}$
1b, $\mathrm{R}=\mathrm{CF}_{3}, \mathrm{X}=\mathrm{NH}_{2}$
1c, $\mathrm{R}=\mathrm{CF}_{3}, \mathrm{X}=\mathrm{OCH}_{3}$
1d, $\mathrm{R}=\mathrm{CF}_{3}, \mathrm{X}=\mathrm{CH}_{3}$
1e, $\mathrm{R}=\mathrm{CF}_{3}, \mathrm{X}=\mathrm{CN}$
1f, $\mathrm{R}=\mathrm{CF}_{3}, \mathrm{X}=\mathrm{NO}_{2}$
1g, $\mathrm{R}=\mathrm{CF}_{3}, \mathrm{X}=\mathrm{SO}_{2} \mathrm{CF}_{3}$
2a, $\mathrm{R}=\mathrm{CH}_{3}, \mathrm{X}=\mathrm{H}$
2b, $\mathrm{R}=\mathrm{CH}_{3}, \mathrm{X}=\mathrm{NH}_{2}$
2c, $\mathrm{R}=\mathrm{CH}_{3}, \mathrm{X}=\mathrm{OCH}_{3}$
2d, $\mathrm{R}=\mathrm{CH}_{3}, \mathrm{X}=\mathrm{CH}_{3}$
2e, $\mathrm{R}=\mathrm{CH}_{3}, \mathrm{X}=\mathrm{CN}$
2f, $\mathrm{R}=\mathrm{CH}_{3}, \mathrm{X}=\mathrm{NO}_{2}$
$2 \mathrm{~g}, \mathrm{R}=\mathrm{CH}_{3}, \mathrm{X}=\mathrm{SO}_{2} \mathrm{CF}_{3}$

These results imply that the anthryl ring stabilizes more efficiently the negative charge in the carbanion than the alkoxide (Scheme 1). The resonance effects on the alkoxide are absent; while the resonance effects on the carbanion are present and the negative charge ought to be delocalized mainly on the $\mathrm{C}-11$ and $\mathrm{C}-10$ carbon atoms. Therefore, an ambident nucleophilic character should be observed for the carbanion, and there would be an electrophilic attack on the C-11 and C-10 carbon atoms.

Scheme 1. The resonance effects on the $\mathrm{OH}$ and $\mathrm{CH}$ ionization and the ambident nucleophilic character for the carbanion.

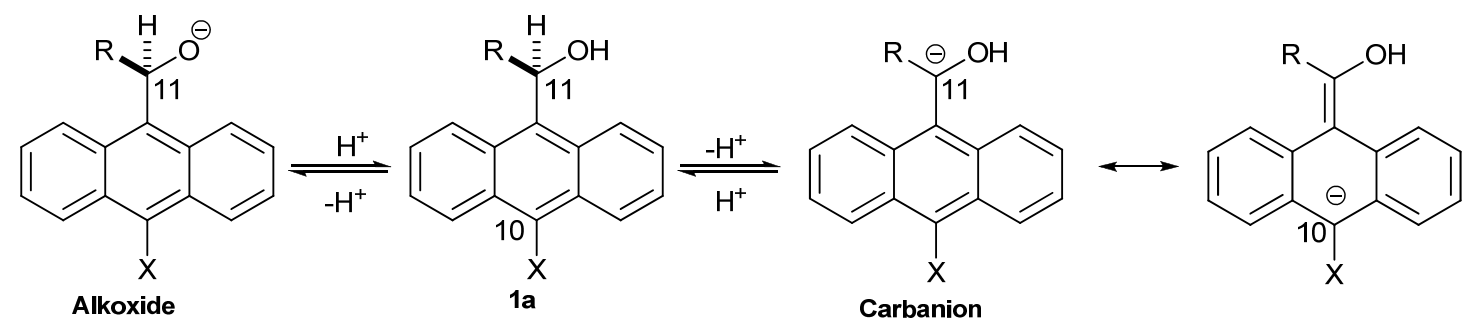

The proposal is consistent with the ambident nucleophilic character experimentally observed for the 9-anthrylmethyl carbanion and related intermediates [9]. Also, it has been reported that the electrophilic attack on (9-anthryl)phenylmethyl and related anions gave the mixture of the two expected products (electrophilic addition on the $\mathrm{C}-11$ and $\mathrm{C}-10$ carbon atoms), whose composition depended of the substituent attached to the phenyl ring of the substrate [10]. However, experimental studies concerning the acidity of $\mathrm{OH}$ and $\mathrm{CH}$ of $\mathbf{1 a}$ and $\mathbf{2 a}$, the ambident nucleophilic character and the origin of the stability for their carbanions $v s$. alkoxides have not been carried out so far. Therefore, we take 1a, 2a, and their derivatives containing $X$ electron-releasing $\mathbf{1 b}-\mathbf{1 d}$ and $\mathbf{2 b - 2 d}$, and $X$ electron-acceptor $\mathbf{1 e}-\mathbf{1 g}$ and $\mathbf{2 e - 2 g}$ substituent attached to C-10 (Figure 1) as a set of alcohols. The 
Fukui function, a density functional theory (DFT) descriptor [11,12], the local hard and soft acids and bases principle (HSAB) $[13,14]$, and the molecular electrostatic potential (MEP) $[15,16]$ were used to demonstrate, in terms of the electron density, that the resonance effects in the carbanions are responsible for the ambident nucleophilic character and stability with respect to the alkoxides, due to the delocalization of the electron density on the C-11 and C-10 carbon atoms.

\section{Results and Discussion}

Table 1 shows the $\Delta_{\text {acid }} G^{\circ}(\mathrm{CH})$ and $\Delta_{\text {acid }} G^{\circ}(\mathrm{OH})$ values obtained for the ionization reactions shown in Scheme 1 for $\mathbf{1 b}-\mathbf{1 g}$ and $\mathbf{2 b}-\mathbf{2 g}$. The calculated acidity values are consistent with the substituent electronic effect, being the alcohol with $\mathrm{X}=\mathrm{NH}_{2}$ (compounds $\mathbf{1 b}, \mathbf{2 b}$ ) the least acidic and with $\mathrm{X}=\mathrm{SO}_{2} \mathrm{CF}_{3}$ (compounds $\mathbf{1 g}, \mathbf{2 g}$ ) the most acidic; they correspond to the two extremes for which $\Delta_{\text {acid }} G^{\circ}(\mathrm{CH})$ and $\Delta_{\text {acid }} G^{\circ}(\mathrm{OH})$ values decrease over 40 and $18 \mathrm{kcal} / \mathrm{mol}$, respectively. The $\mathrm{CH}$ acidity is higher than the $\mathrm{OH}$ acidity for $\mathbf{1 e}-\mathbf{1 g}$ and $\mathbf{2 b}-\mathbf{2 g}$ (positive $\delta \Delta_{\text {acid }} G^{\circ}$ values), which implies that the carbanions $\mathbf{1 e}-\mathbf{1 g}$ and $\mathbf{2 b}-\mathbf{2 g}$ are more stable than the alkoxides by 3.1-12.4 and 3.8-26.1 kcal mol ${ }^{-1}$ respectively.

Table 1. Absolute gas phase acidities for alcohols $\mathbf{1 b}-\mathbf{2 g}$. Values are reported in kcal $\operatorname{mol}^{-1} . \delta \Delta_{\text {acid }} G^{\circ}=\Delta_{\text {acid }} G^{\circ}(\mathrm{OH})-\Delta_{\text {acid }} G^{\circ}(\mathrm{CH})$.

\begin{tabular}{cccc}
\hline Alcohol & $\Delta_{\text {acid }} G^{\circ}(\mathbf{C H})$ & $\Delta_{\text {acid }} G^{\circ}(\mathbf{O H})$ & $\delta \Delta_{\text {acid }} G^{\circ}$ \\
\hline 1b (2b) & $349.8(352.3)$ & $342.1(356.2)$ & $-7.7(3.9)$ \\
$\mathbf{1 c ( 2 c )}$ & $346.3(347.8)$ & $339.3(353.4)$ & $-7.0(5.6)$ \\
$\mathbf{1 d ~ ( 2 d )}$ & $345.1(348.0)$ & $339.9(353.3)$ & $-5.2(5.3)$ \\
$\mathbf{1 e ~ ( 2 e )}$ & $327.2(328.5)$ & $330.3(344.1)$ & $3.1(15.6)$ \\
$\mathbf{1 f ( 2 f )}$ & $319.9(318.6)$ & $330.5(343.7)$ & $10.6(25.1)$ \\
$\mathbf{1 g}(\mathbf{2 g})$ & $313.1(311.9)$ & $325.6(338.0)$ & $12.5(26.1)$ \\
\hline
\end{tabular}

Negative $\delta \Delta_{\text {acid }} G^{\circ}$ values for $\mathbf{1 b}-\mathbf{1 d}$ indicate that the electron-releasing substituent is not efficient enough to delocalize the negative charge into the aromatic ring; the carbanions of $\mathbf{1 b}-\mathbf{1} \mathbf{d}$ are less stable than the alkoxides by $7.7-5.2 \mathrm{kcal} \mathrm{mol}^{-1}$ respectively. Therefore, the stability of the carbanions of 1 and 2 increases as the electron-acceptor capacity of the substituent increases [17]. The correlation between the electronic effect of $\mathrm{X}$ and the ionization reactions of Scheme 1, is evident from the good linear regression analysis obtained for $\Delta_{\text {acid }} G^{\circ}(\mathrm{CH})$ or $\Delta_{\text {acid }} G^{\circ}(\mathrm{OH})$ and the Hammett substituent constants in the gas $\sigma_{\mathrm{p}}{ }^{-}$(g) or aqueous $\sigma_{\mathrm{p}}{ }^{-}$(aq) phase (see Table 2) [18]. The slope values are quite large and negative for $\Delta_{\text {acid }} G^{\circ}(\mathrm{CH})$ as would be expected for the generation of a large amount of negative charge upon the ring. On the other hand the lower slope values for $\Delta_{\text {acid }} G^{\circ}(\mathrm{OH})$ indicates localized negative charge on oxygen atom, but not transmittable to the ring [19].

While, the resonance effects on the $\mathrm{CH}$ ionization are present, the delocalization of the negative charge of the carbanions into the ring can be illustrated in terms of resonance theory [20]. The Kekulé resonance structures I-VII on Scheme 2 show that the negative charge is localized on the C-2 (II), C-4 (III), C-10 (IV), C-5 (V), C-7 (VI), C-11(I) carbon atoms, and on the substituent X (VII). The classical Kekulé structures $\mathbf{A}_{1}$ and $\mathbf{A}_{\mathrm{r}}$ are structures in which double bond alternation extends over the whole periphery of the molecule [21]. 
Table 2. Linear correlation equation between $\Delta_{\text {acid }} G^{\circ}(\mathrm{CH})$ or $\Delta_{\text {acid }} G^{\circ}(\mathrm{OH})$ and ${\sigma_{\mathrm{p}}}^{-}{ }_{(\mathrm{g})},{\sigma_{\mathrm{p}}}^{-}$(aq) or $\chi_{\mathrm{XC}_{6} \mathrm{H}_{4}}$ for $\mathbf{1 b}-\mathbf{1 g}$. The linear correlation equation for $\mathbf{2 b - 2} \mathbf{g}$ is given in parenthesis. $\Delta_{\text {acid }} G^{\circ}=\mathrm{b}+\mathrm{mY}\left(\right.$ values in $\left.\mathrm{kcal} \mathrm{mol}^{-1}\right)$.

\begin{tabular}{ccccc}
\hline $\mathbf{Y}$ & $\boldsymbol{\Delta}_{\text {acid }} \boldsymbol{G}^{\circ}$ & $\mathbf{b}$ & $\mathbf{M}$ & $\mathbf{R}^{\mathbf{2}}$ \\
\hline & & 344.9 & -23.0 & 0.99 \\
$\sigma_{\mathrm{p}_{(\mathrm{g})}}^{-}$ & $\mathrm{CH}$ & $(347.1)$ & $(-25.2)$ & $(0.98)$ \\
& $\mathrm{OH}$ & 339.2 & -9.7 & 0.96 \\
& & $(353.3)$ & $(-1.0)$ & $(0.97)$ \\
\hline \multirow{2}{*}{$\sigma_{\mathrm{p}_{(\mathrm{aq})}^{-}}$} & $\mathrm{CH}$ & 345.6 & -20.1 & 0.97 \\
& $\mathrm{OH}$ & $3343.6)$ & $(-18.2)$ & $(0.98)$ \\
& & $(352.7)$ & -7.7 & 0.95 \\
& & 472.5 & -24.7 & 0.98 \\
$\chi_{\mathrm{XC}_{6} \mathrm{H}_{4}}$ & $\mathrm{CH}$ & $(488.0)$ & $(-27.3)$ & $(0.97)$ \\
& $\mathrm{OH}$ & 393.3 & -10.4 & 0.98 \\
& & $(409.2)$ & $(-10.8)$ & $(0.99)$ \\
\hline
\end{tabular}

Scheme 2. The Kekulé resonance structures for the carbanion.

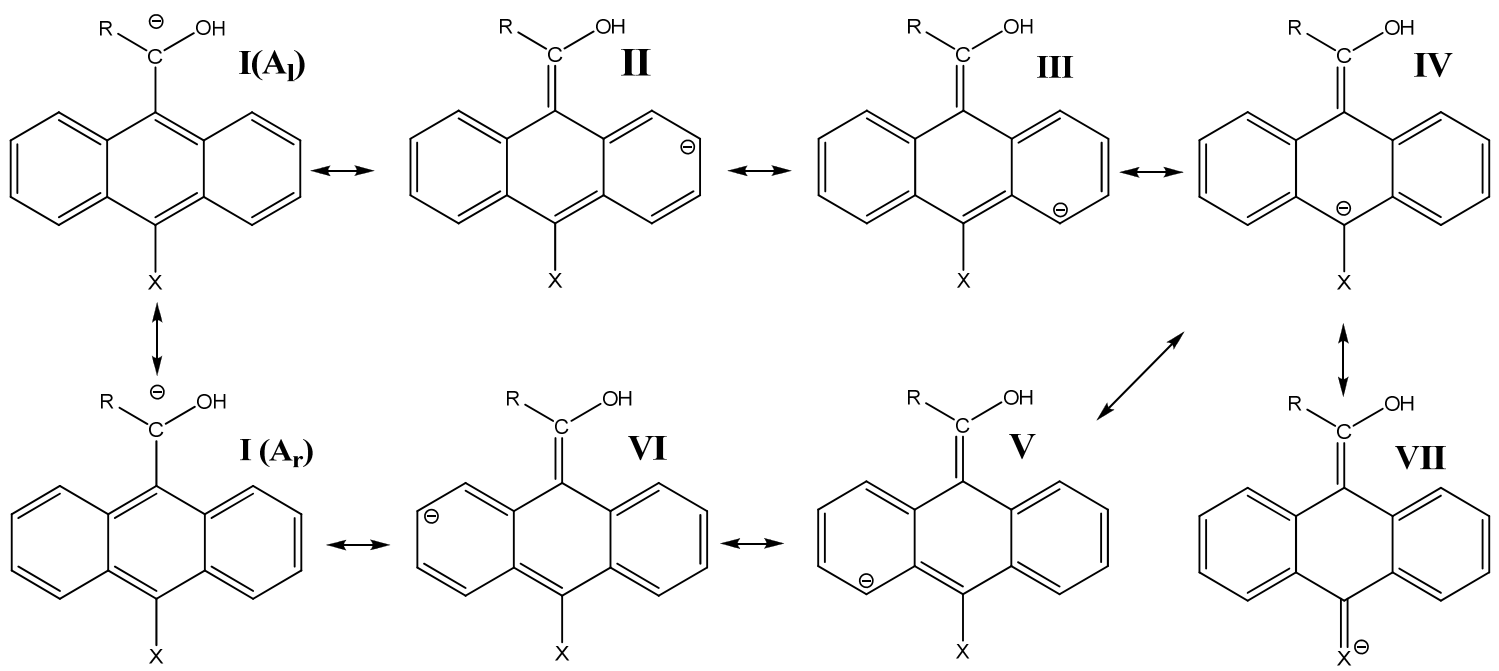

We have shown previously that the resonance hybrid structure can be described in terms of the Fukui function [22]. The Fukui function $f(\mathbf{r})$ represents the change of the electronic density $\rho(\mathbf{r})$ in a given point with respect to the change in the number of electrons $\mathrm{N}, f(\mathbf{r})=(\partial \rho / \partial N)$, and the stability of the ion can be achieved from the link between $f(\mathbf{r})$ and the energy $\mathrm{E}$ of the system $f(\mathbf{r})=[\delta(\partial E / \partial N) / \delta v(\mathbf{r})]_{N}[11,12]$, where $v(\mathbf{r})$ is the external potential associated to the nucleus. The amount of charge in the carbanions and alkoxides was examined specifically from the Fukui function for electrophilic attack $f(\mathbf{r})$ (Figures 2-4) and the local HSAB principle [13,14]. Figure 2 shows that the largest values of $f(\mathbf{r})$ for $\mathbf{1 a}$ and $\mathbf{2 a}$ are located on the $\mathrm{O}$ and the $\mathrm{C}-11 / \mathrm{C}-10$ atoms for the alkoxides and carbanions respectively. They are associated with softer nucleophilic regions $\left(s^{-}(\mathbf{r})=\mathrm{S} f(\mathbf{r})\right)$, by giving up electronic charge and are especially reactive toward soft electrophiles [13]. Therefore, charge localization occurs on the strongly electronegative oxygen atom for the alkoxides; whereas, the charge 
is located on the $\mathrm{C}-11 / \mathrm{C}-10$ carbon atoms indicating an ambident soft nucleophilic character for the carbanions and the distribution of the anionic charge into the ring is represented in terms of the resonance structures $\mathbf{I}$ and $\mathbf{I V}$.

Figure 2. The surface plot of the electrophilic Fukui function for the alkoxides $\left(\mathrm{O}^{-}\right)$and carbanions $\left(\mathrm{C}^{-}\right)$of $\mathbf{1 a}$ and $\mathbf{2 a}$.
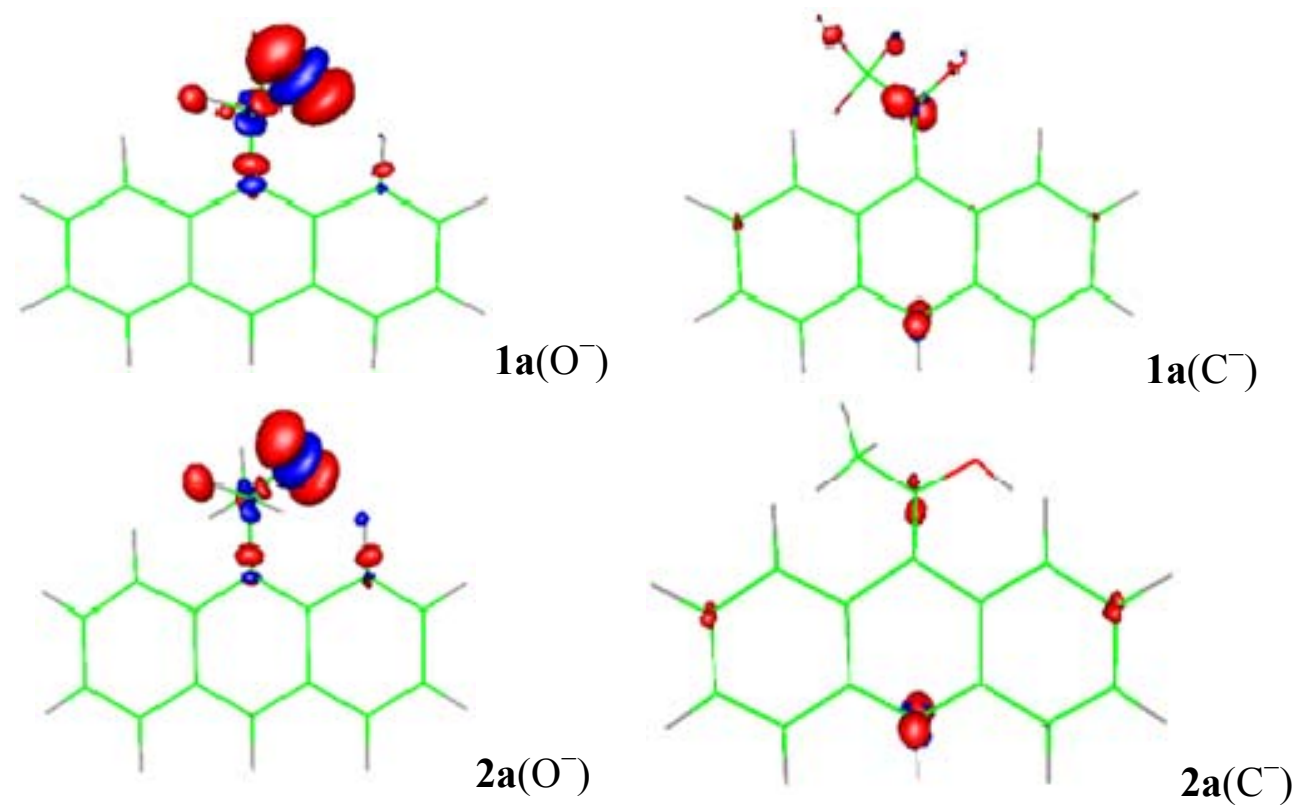

Figure 3. The surface plot of the electrophilic Fukui function for the alkoxides $\left(\mathrm{O}^{-}\right)$and carbanions $\left(\mathrm{C}^{-}\right)$of $\mathbf{1 b}$ and $\mathbf{2 b}$.

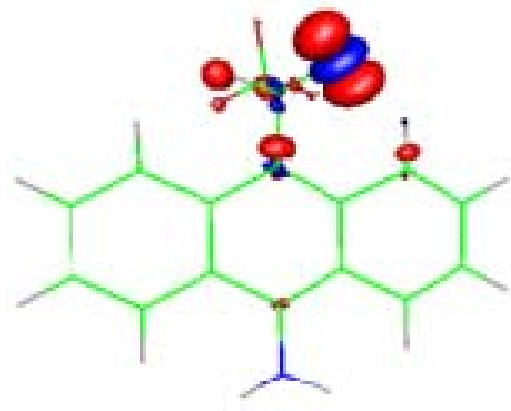

$1 \mathbf{b}\left(\mathrm{O}^{-}\right)$
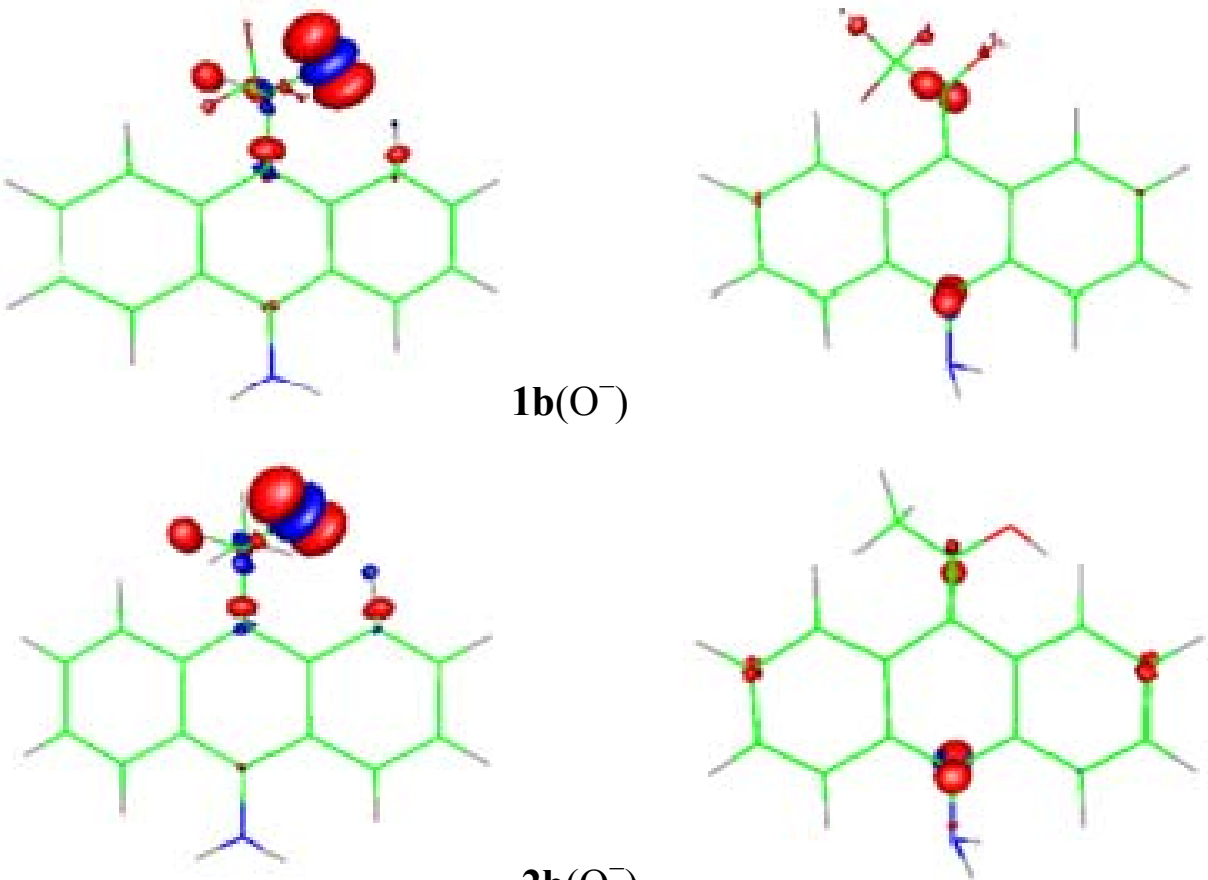

$2 \mathbf{b}\left(\mathrm{O}^{-}\right)$

$1 \mathbf{b}\left(\mathrm{C}^{-}\right)$

$2 \mathbf{b}\left(\mathrm{C}^{-}\right)$

When the $\mathrm{NH}_{2}$ electron-releasing substituent is included (Figure 3), the behavior of the $f(\mathbf{r}$ ) for $\mathbf{1 b}$ and $\mathbf{2 b}$ is almost similar to that of $\mathbf{1 a}$ and $\mathbf{2 a}$; the largest values of $f(\mathbf{r})$ are located on the $\mathrm{O}$ and the 
C-11/C-10 atoms. The $\mathrm{NH}_{2}$ substituent has no contribution to the charge dispersal. For the alkoxide charge localization occurs on the strongly electronegative oxygen atom; whereas, for the carbanion the charge dispersion involved the $\mathrm{C}-11 / \mathrm{C}-10$ carbon atoms indicating an ambident soft nucleophilic character that is well represented by resonance structures I and IV (Scheme 2). The generation of a small amount of negative charge upon the ring makes the carbanion of $\mathbf{1 b} 7.7 \mathrm{kcal} \mathrm{mol}^{-1}$ less stable than the corresponding alkoxide. The carbanion of $\mathbf{2} \mathbf{b}$ delocalizes the negative charge into the aromatic ring more efficiently than that of $\mathbf{1 b}$ due the $f(\mathbf{r})$ trends for $\mathbf{1 b}$ and $\mathbf{2} \mathbf{b}$ are $\mathbf{C}-11>\mathbf{C}-10$ and $\mathrm{C}-11<\mathrm{C}-10$ respectively; the carbanion of $\mathbf{2 b}$ is $3.9 \mathrm{kcal} \mathrm{mol}^{-1}$ more stable than the corresponding alkoxide (See Table 1). The results are similar for $\mathrm{X}=\mathrm{OCH}_{3}$ and $\mathrm{CH}_{3}($ See Figures in the Electronic Supplementary Information).

Figure 4. The surface plot of the electrophilic Fukui function for the alkoxides $\left(\mathrm{O}^{-}\right)$and carbanions $\left(\mathrm{C}^{-}\right)$of $\mathbf{1 f}$ and $\mathbf{2 f}$.

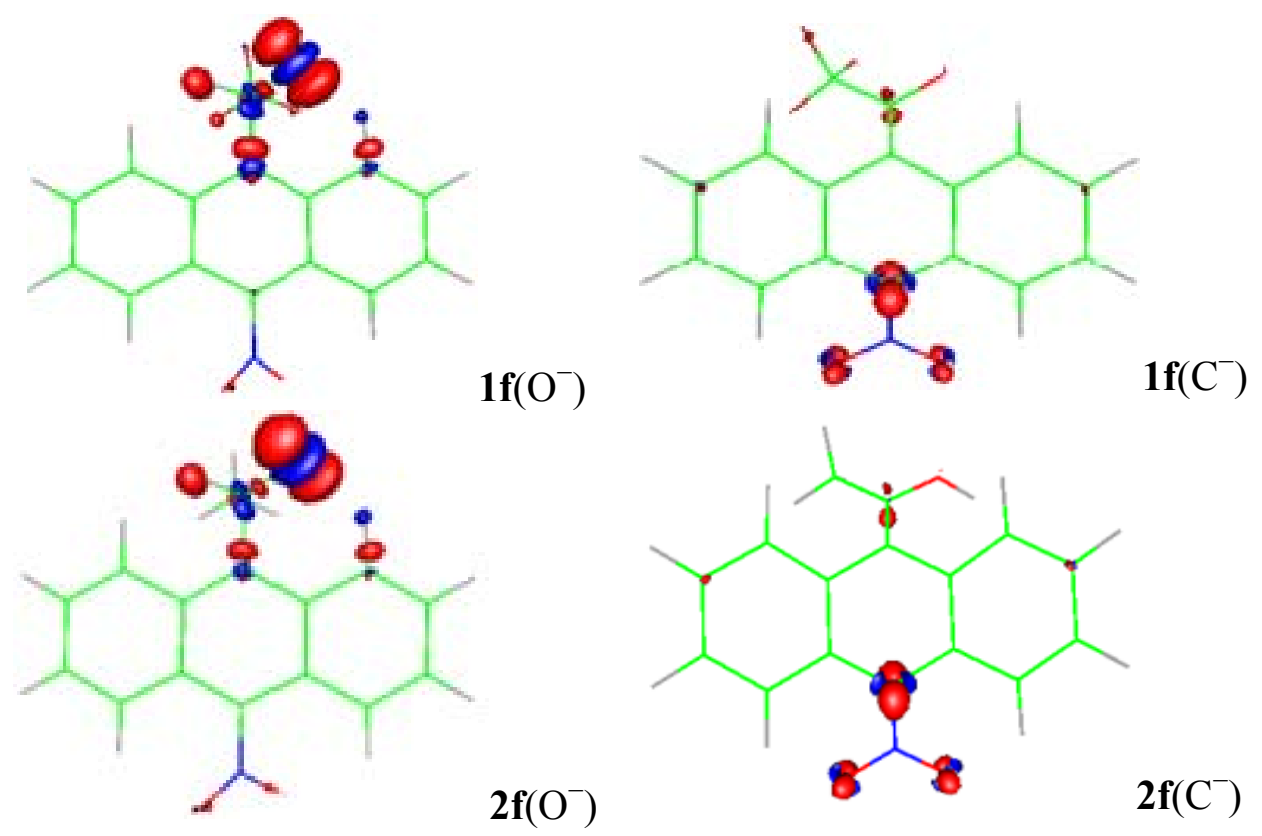

When the $\mathrm{NO}_{2}$ substituent is included (Figure 4), $f(\mathbf{r})$ for the alkoxides of $\mathbf{1 f}$ and $\mathbf{2} \mathbf{f}$ shows localized negative charge on oxygen atom, but not transmittable to the ring. For the carbanions of $\mathbf{1 f}$ and $\mathbf{2 f}$, $f(\mathbf{r})$ indicates generation of a large amount of negative charge localized on $\mathrm{C}-10$ and on the $\mathrm{NO}_{2}$ substituent (with most of the negative charge residing on the two oxygen atoms) [23-25], making the carbanions of $\mathbf{1 f}$ and $2 \mathbf{2 f} 10.6$ and $25.1 \mathrm{kcal} \mathrm{mol}^{-1}$ more stable than their alkoxides respectively (see Table 1). Therefore, the distribution of the anionic charge into the ring is represented in terms of the resonance structures IV and VII (Scheme 2). The results are similar for $\mathrm{X}=\mathrm{CN}$ and $\mathrm{SO}_{2} \mathrm{CF}_{3}$ (see figures in the Supplementary Information).

As we can observe, the Fukui function for electrophilic attack shows that delocalization of the anionic charge mainly occurs in the central ring of the 9-anthryl group, making the central ring more reactive than the edge rings for soft-soft interactions. This important result can be supported by the electronegativity of the central ring effect of the 9-anthryl group on the $\Delta_{\text {acid }} G^{\circ}(\mathrm{CH})$ or $\Delta_{\text {acid }} G^{\circ}(\mathrm{OH})$.

The electronegativity of the central ring can be approximated by the $\mathrm{XC}_{6} \mathrm{H}_{4}$ fragment electronegativity $\chi \mathrm{xC}_{6} \mathrm{H}_{4}$ calculated previously for a set of $p$-substituted phenols $\mathrm{XC}_{6} \mathrm{H}_{4} \mathrm{OH}$ [7]. From 
Table 2 we can observe the negative slope values; the acidity increases ( $\Delta_{\text {acid }} G^{\circ}$ decreases) when $\chi \mathrm{XC}_{6} \mathrm{H}_{4}$ increases, validating the proposal that the central ring exhibits more contribution to $\Delta_{\text {acid }} G^{\circ}$ than the edge rings and it behaves as a rather separated benzenoid ring or localized entity. This is a nice coincidence with the ambident nucleophilic character experimentally observed for the 9-anthrylmethyl carbanion and related intermediates [26], and the calculated aromaticity of the central ring of anthracene [27-29].

Figures 5-7 show the molecular electrostatic potential (MEP) $[15,16]$ mapped onto an isosurface of the total electron density for the alkoxides and carbanions of $\mathbf{1 a - 2 a}$, and $\mathbf{1 f}-\mathbf{2 f}$ respectively. The MEP can be appropriate for analyzing hard-hard interactions because the proton (a hard electrophile) prefers a site with maximum net charge [13,30]. In Figure 5, we observe the MEP for the alkoxides and carbanions of $\mathbf{1 a}$ and $\mathbf{2 a}$, in these anions, the blue area, towards the oxygen (1a and 2a) and fluorine atoms (1a), indicates higher negative charge; the red color, located near the hydrogen atoms and methyl group indicate more positive charge and lower electron density.

Figure 5. MEP mapped onto an isosurface of the total electron density for the alkoxides $\left(\mathrm{O}^{-}\right)$and carbanions $\left(\mathrm{C}^{-}\right)$of $\mathbf{1 a}$ and $\mathbf{2 a}$.
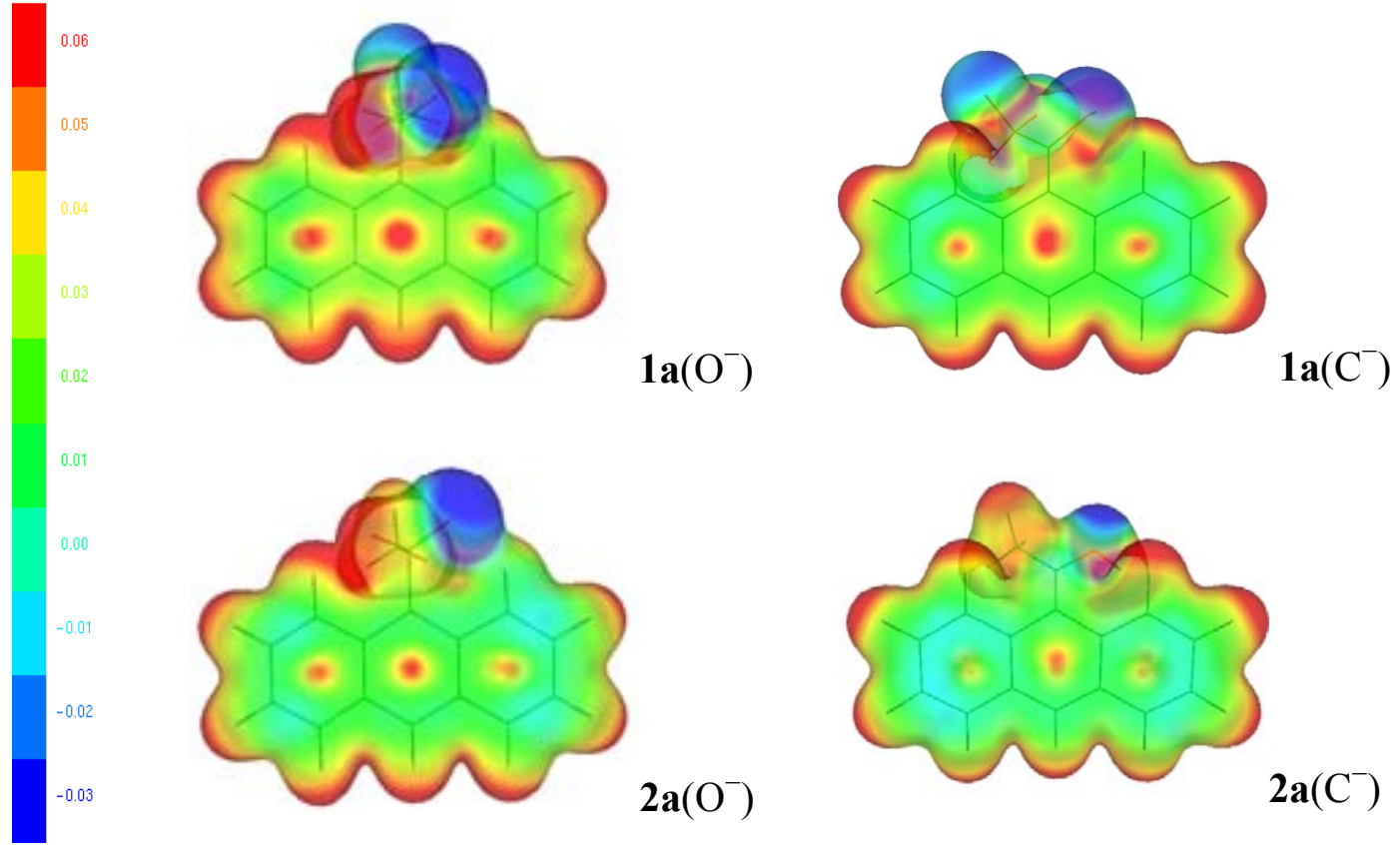

We notice an uneven distribution of electrons with positive charge in the 9-anthryl ring, the central ring exhibits more positive charge than the edge rings. That is, in the alkoxides and carbanions of 1a and 2a, the hydrogen atoms are more positive (red color) than the carbon atoms of the 9-anthryl ring and the $\mathrm{C}-11$ carbon atom, and the oxygen and fluorine atoms are more negative (blue colors). When the $\mathrm{NH}_{2}$ electron-releasing substituent is included (Figure 6), the behavior of the MEP for the $\mathbf{2 b}$, the hydrogen atoms are more positive (red color) than the 9-anthryl ring and the $\mathrm{C}-11$ carbon atom. The oxygen, nitrogen and fluorine atoms are more negative (blue colors). The results are similar for $\mathrm{X}=\mathrm{OCH}_{3}$ and $\mathrm{CH}_{3}$ (see figures in the Supplementary Information). 
Figure 6. MEP mapped onto an isosurface of the total electron density for the alkoxides $\left(\mathrm{O}^{-}\right)$and carbanions $\left(\mathrm{C}^{-}\right)$of $\mathbf{1 b}$ and $\mathbf{2 b}$.
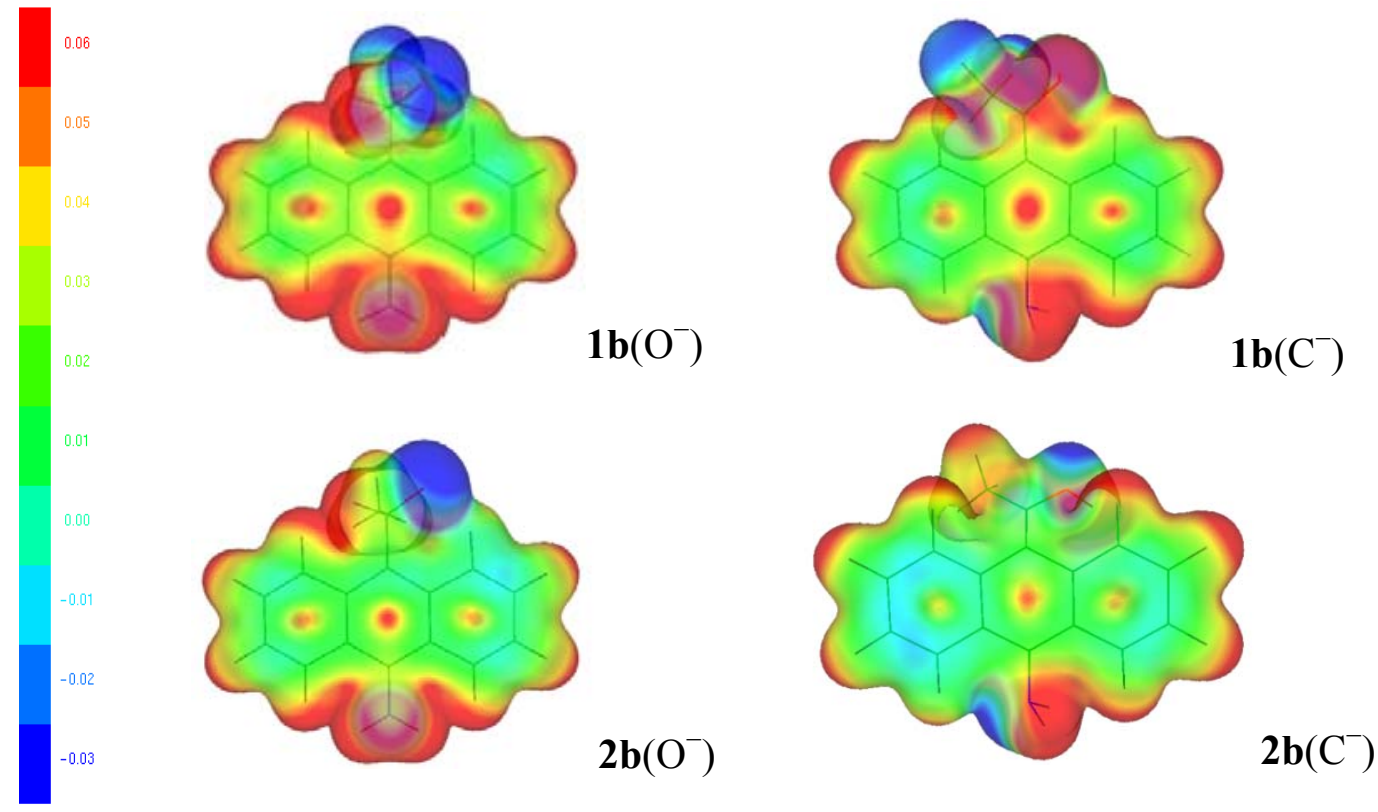

Figure 7. MEP mapped onto an isosurface of the total electron density for the alkoxides $\left(\mathrm{O}^{-}\right)$and carbanions $\left(\mathrm{C}^{-}\right)$of $\mathbf{1 f}$ and $\mathbf{2 f}$.
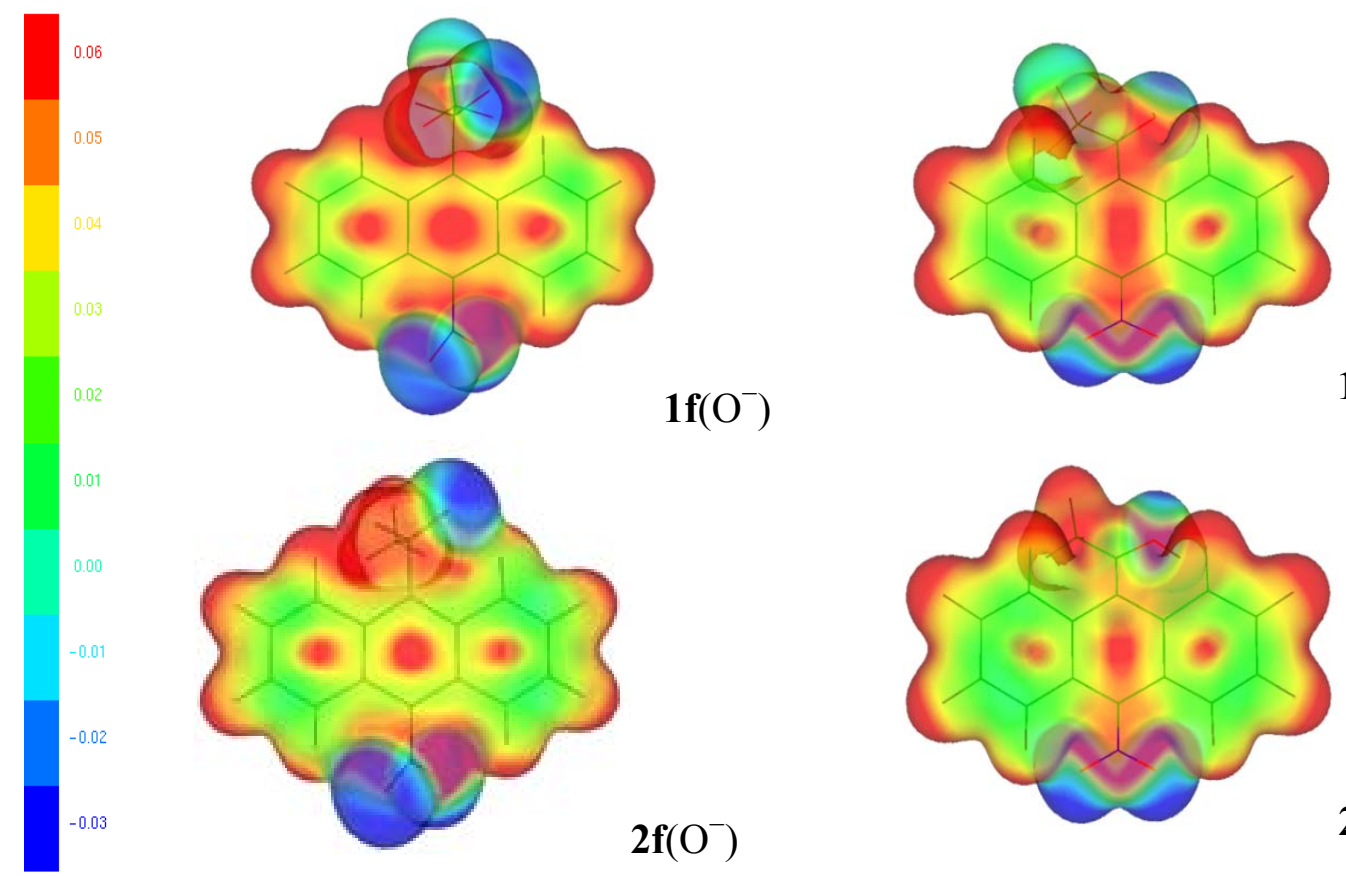

$\mathbf{1 f}\left(\mathrm{C}^{-}\right)$

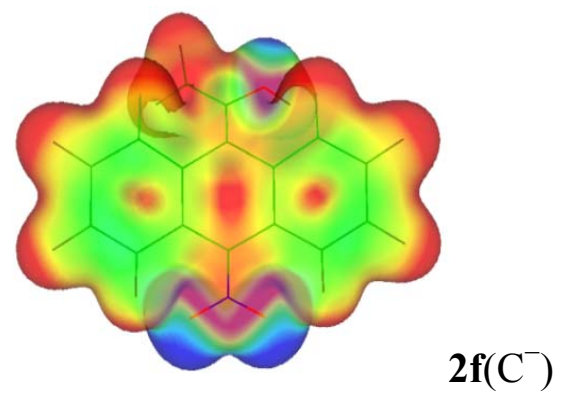

In Figure 7, we observe the MEP for the alkoxides and carbanions of $\mathbf{1 f}$ and $\mathbf{2 f}$, in these anions, the blue negative area is located towards the oxygen, nitrogen (compounds $\mathbf{1 f}$ and $\mathbf{2 f}$ ) and fluorine atoms (1f); the red color is located near the hydrogen atoms, methyl group, $\mathrm{C}-11$ carbon atom and the 9-anthryl ring. The uneven distribution of electrons with positive charge in the 9-anthryl ring is observed, the central ring exhibits more positive charge than the edge rings, indicating lower electron density than in the anions of $\mathbf{1 a}-\mathbf{2 a}$ and $\mathbf{1 b}-\mathbf{2} \mathbf{b}$. The results are similar for $\mathrm{X}=\mathrm{CN}$ and $\mathrm{SO}_{2} \mathrm{CF}_{3}$ 
(see figures in the Supplementary Information). Therefore, the proton (a hard electrophile) prefers the oxygen (alkoxides 1 and 2) and fluorine atoms (alkoxide 1) with maximum MEP (the blue area with higher negative charge).

\section{Theoretical Methodology}

The ground state structures and energies of alcohols $\mathbf{1 a - 2 g}$ were calculated at the B3LYP/6-31+G(d,p) level of theory using GAUSSIAN03 [31]. The thermodynamic stability of the carbanions and alkoxides of $\mathbf{1 a}-\mathbf{2 g}$ was obtained from the calculated $\mathrm{CH}$ and $\mathrm{OH}$ absolute gas-phase acidities [32]. Gas phase studies are required to separate intrinsic molecular properties from interfering solvation effects [33]. The absolute gas-phase acidity $\Delta_{\text {acid }} G^{\circ}$ is given by $\Delta_{\text {acid }} G^{\circ}=G^{\circ}$ (anion) $+G^{\circ}(\mathrm{H}+)-G^{\circ}$ (alcohol) [34]. The Gibbs free energies $G^{\circ}$ (anion), $G^{\circ}($ alcohol) and $G^{\circ}(\mathrm{H}+)$ were obtained by means of partition functions using statistical thermodynamic relationships [35]. The electrophilic Fukui function and the electrostatic potential of the molecules were visualized throughout by the gOpenmol software [36].

\section{Conclusions}

The nucleophilic character and the relative stability of the carbanions $v s$. the corresponding alkoxides of 1-(9-anthryl)ethanol and its derivatives has been studied in terms of the absolute gas phase acidity, Fukui function, the local HSAB bases principle and the molecular electrostatic potential. The central ring of the 9-anthryl group stabilizes more efficiently the conjugated carbanion than the oxygen atom of the alkoxide by electron-acceptor delocalization; as a consequence the negative charge is delocalized on the $\mathrm{C}-11$ and $\mathrm{C}-10$ carbon atoms that is well represented for the resonance structures I and IV. The C-11 and C-10 carbon atoms with maximum Fukui function give an ambident soft nucleophilic character to the carbanions $\mathbf{1}$ and $\mathbf{2}$. The $\mathrm{X}$ substituent has an important contribution to the negative charge dispersal. Therefore, the negative charge is localized on the oxygen atom of the alkoxide, but nor transmittable to the ring; the proton (a hard electrophile) prefers the oxygen (alkoxides 1 and 2) and fluorine atoms (alkoxide 1) with maximum MEP (the blue area with higher negative charge) [37]. The results obtained in this work open the possibility to analyze the stability of anions as a result of the delocalization of the anionic charge in terms of the electron density. Studies related to the experimental reactivity of $\mathbf{1 a - 1 f}$ are underway and will be reported in due course.

\section{Supplementary Materials}

Supplementary materials can be accessed at: http://www.mdpi.com/1420-3049/18/9/10254/s1.

\section{Acknowledgments}

This work has been supported by research grants 180523, 163234, 61626 and 32261E from Consejo Nacional de Ciencia y Tecnología de México (CONACyT), who also supported Ramsés. E. Ramírez with a Ph.D. scholarship 134559. The authors acknowledge the insightful comments of Hugo A. Jiménez-Vázquez. 


\section{Conflicts of Interest}

The authors declare no conflict of interest.

\section{References and Notes}

1. Wenzel, T.J.; Wilcox, J.D. Chiral reagents for the determination of enantiomeric excess and absolute configuration using NMR spectroscopy. Chirality 2003, 15, 256-270.

2. García-Martínez, C.; Cervantes, H.; Méndez, F.; Escalante, J. Stoichiometry, association constant, and solvation model of chiral hydroxyfuranones in the presence of Pirkle's alcohols. J. Spectrosc. Lett. 2011, 44, 168-175.

3. Pirkle, W.H.; Finn, J.M. Chiral high-pressure liquid chromatographic stationary phases. 3. General resolution of arylalkylcarbinols. J. Org. Chem. 1981, 46, 2935-2938.

4. Pirkle, W.H.; Hoover, D.J. Topics in Stereochemistry; Allinger, N.L., Eliel, E.L., Wilen, S.H., Eds.; John Wiley\& Sons: New York, NY, USA, 1982; Volume 13, pp. 263-331.

5. Stewart, R.; van der Linden, R. The acidity of some aromatic fluoro alcohols and ketones. Can. J. Chem. 1960, 38, 399-406.

6. Ramírez, E.R.; García-Martínez, C.; Méndez, F. Influence of fluorine atoms and aromatic rings on the acidity of ethanol. J. Phys. Chem. A 2009, 113, 10753-10758.

7. Romero, M.L.; Méndez, F. Is the hydrogen atomic charge representative of the acidity of parasubstituted phenols? J. Phys. Chem. A 2003, 107, 4526-4530.

8. Romero, M.L.; Méndez, F. The local HSAB principle and bond dissociation energy of $p$-substituted phenol. J. Phys. Chem. A 2003, 107, 5874-5875.

9. Engler, T.A.; Shechter, H. Generation and the ambident character of 9-anthrylmethyl carbanions. Tetrahedron Lett. 1983, 24, 4645-4648.

10. Takagi, M.; Nojima, M.; Kusabayashi, S. Protonation and alkylation of ambident (9-anthryl)arylmethyl anions. J. Am. Chem. Soc. 1983, 105, 4676-4684.

11. Parr, R.G.; Yang, W. Density Functional Theory of Atoms and Molecules; Oxford University Press: New York, NY, USA, 1989.

12. Lee, C.; Yang, W.; Parr, R.G. Local softness and chemical reactivity in the molecules CO, $\mathrm{SCN}^{-}$ and $\mathrm{H}_{2}$ CO. J. Mol. Struct. 1988, 163, 305-313.

13. Pearson, R.G. Hard and soft acids and bases. J. Am. Chem. Soc. 1963, 85, 3533-3539.

14. Méndez, F.; Gázquez, J.L. Chemical reactivity of enolate ions: The local hard and soft acids and bases principle viewpoint. J. Am. Chem. Soc. 1994, 116, 9298-9301.

15. Levine, I. Quantum Chemistry, 5th ed.; Prentice Hall: Upper Saddle River, NJ, USA, 2001; pp. 493-495.

16. Politzer, P.; Murray, J.S.; Lipkowitz, K.B.; Boyd, D.B. Molecular Electrostatic Potentials and Chemical Reactivity, in Reviews in Computational Chemistry; Wiley-VCH: Hoboken, NJ, USA, 1991; Volume 2, Chapter 7.

17. Berger, S.T.A.; Ofial, A.R.; Mayr, H. Inverse solvent effects in carbocation carbanion combination reactions: The unique behavior of trifluoromethylsulfonyl stabilized carbanions. J. Am. Chem. Soc. 2007, 129, 9753-9761. 
18. Hansch, C.; Leo, A.; Taft, R.W. A survey of Hammett substituent constants and resonance and field parameters. Chem. Rev. 1991, 91, 165-195.

19. Taft, R.W.; Bordwell, F.G. Structural and solvent effects evaluated from acidities measured in dimethyl sulfoxide and in the gas phase. Acc. Chem. Res. 1988, 21, 463-469.

20. Smith, M.B.; March, J. March's Advanced Organic Chemistry: Reactions, Mechanisms, and Structure; John Wiley \& Sons, Inc.: New York, NY, USA, 2001; pp. 32-97.

21. Shaik, S.; Zilberg, S.; Haas, Y. A kekulé-crossing model for the "anomalous" behavior of the $b_{2 u}$ modes of aromatic hydrocarbons in the lowest excited ${ }^{1} \mathrm{~B}_{2 u}$ state. Acc. Chem. Res. 1996, 29 , 211-218.

22. López, P.; Méndez, F. Fukui function as a descriptor of the imidazolium protonated cation resonance hybrid structure. Org. Lett. 2004, 6, 1781-1783.

23. Gázquez, J.L.; Méndez, F. The hard and soft acids and bases principle: An atoms in molecules viewpoint. J. Phys. Chem. 1994, 98, 4591-4593.

24. Chattaraj, P.-K. Chemical reactivity and selectivity: Local HSAB principle versus frontier orbital theory. J. Phys. Chem. A 2001, 105, 511-513.

25. Méndez, F.; Galván, M.; Garritz, A.; Vela, A.; Gázquez, J.L. Local softness and chemical reactivity of maleimide: nucleophilic addition. J. Mol. Struct. 1992, 277, 81-86.

26. Experimental results suggested the same effects for $\mathrm{NO}_{2}$ and $\mathrm{SO}_{2} \mathrm{CF}_{3}$ in nitro and triflinate stabilized 9-anthrylmethyl carbanions.

27. Wheland, G.W. Resonance in Organic Chemistry; Wiley: New York, NY, USA, 1955; p. 517.

28. Schleyer, P.R.; Manoharan, M.; Jiao, H.; Stahl, F. The acenes: Is there a relationship between aromatic stabilization and reactivity? Org. Lett. 2001, 3, 3643-3646.

29. Aihara, J.; Kanno, H. Local aromaticities in large polyacene molecules. J. Phys. Chem. A 2005, 109, 3717-3721.

30. Chigo-Anota, E.; Ramírez-Gutierrez, R.E.; Escobedo-Morales, A.; Hernández-Cocoletzi, G. Influence of point defects on the electronic properties of boron nitride nanosheets. J. Mol. Model. 2012, 18, 2175-2184.

31. M.J.; Trucks, G.W.; Schlegel, H.B.; Scuseria, G.E.; Robb, M.A.; Cheeseman, J.R.; Montgomery, J.A., Jr.; Vreven, T.; Kudin, K.N.; Burant, J.C.; et al. Gaussian 03, Revision C.02; Frisch, Gaussian, Inc.: Wallingford, CT, USA, 2004.

32. Although there are no experimental $\Delta_{\text {acid }} G^{\circ}$ values for $\mathbf{1 a - 1 g}$ and $\mathbf{2 a}-\mathbf{2 g}$ reported in the literature, the B3LYP/6-31+G(d,p) calculated $\Delta_{\text {acid }} G^{\circ}$ values for ethanol, its fluorine derivatives, phenylethanol and $p$-substituted phenols showed a good agreement with the experimental values reported in the literature.

33. Solca, N.; Dopfer, O. Spectroscopic identification of oxonium and carbenium ions of protonated phenol in the gas phase: IR spectra of weakly bound $\mathrm{C}_{6} \mathrm{H}_{7} \mathrm{O}^{+}$-L dimers $(\mathrm{L}=\mathrm{Ne}, \mathrm{Ar}, \mathrm{N} 2) . J . A m$. Chem. Soc. 2004, 126, 1716-1725.

34. Fujio, M.; McIver, R.T., Jr.; Taft, R.W. Effects of the acidities of phenols from specific substituent-solvent interactions. Inherent substituent parameters from gas-phase acidities. J. Am. Chem. Soc. 1981, 103, 4017-4029.

35. McQuarrie, D.A.; Simon, J.D. Molecular Thermodynamics; University Science Books: Sausalito, CA, USA, 1999; pp. 273-285. 
36. The g0penMol is available online: http://www.csc.fi/english/pages/g0penMol (accessed on 22 February 2013).

37. Lum, R.C.; Grabowski, J.J. Intrinsic competition between elimination and substitution mechanisms controlled by nucleophile structure. J. Am. Chem. Soc. 1992, 114, 9663-9665.

Sample Availability: Samples of the compounds 1a and 2a are available from the authors.

(C) 2013 by the authors; licensee MDPI, Basel, Switzerland. This article is an open access article distributed under the terms and conditions of the Creative Commons Attribution license (http://creativecommons.org/licenses/by/3.0/). 